\title{
Expired Paracetamol as Corrosion Inhibitor for Low Carbon Steel in Sulfuric Acid. Electrochemical, Kinetics and Thermodynamics Investigation
}

\author{
Arej S Al-Gorair ${ }^{*}$, M. Abdallah ${ }^{2,3}$ \\ ${ }^{1}$ Chem. Depart., College of Sci., Princess Nourah bint Abdulrahman Univ., Riyadh, Saudi Arabia \\ ${ }^{2}$ Chem. Depart., Fac. of Appl. Sci., Umm Al-Qura Univ., Makkah, Saudi Arabia \\ ${ }^{3}$ Chem. Depart., Faculty of Sci., Benha Univ., Benha, Egypt \\ "E-mail: asalgorir@pnu.edu.sa
}

doi: $10.20964 / 2021.07 .73$

Received: 27 March 2021 / Accepted: 21 May 2021 / Published: 31 May 2021

\begin{abstract}
Expired paracetamol is used as efficient inhibitor for the general and pitting corrosion of low carbon steel (LCS) in $1.0 \mathrm{~mol} \mathrm{~L}^{-1} \mathrm{H}_{2} \mathrm{SO}_{4}$ solution. Three electrochemical tests are used to measure the inhibition efficacy. The inhibition efficacy increases with increasing the concentricity of the expired paracetamol and with lowering temperature. The outcomes indicate the values of corrosion current density and capacity of the double layer decrease while the charge transfer and the inhibition efficacy increase. The values of pitting potential are moved to more positive trend. These outcomes emphasize the inhibitory strength of expired paracetamol. The inhibition can be explicated in term of the spontaneous adsorption of the complex formed between iron (II) ion and paracetamol on the surface LCS. The adsorption followed Langmuir isotherm. The thermodynamics parameters for the activation and adsorption process were assessed from the study of impact temperature
\end{abstract}

Keywords: Low carbon steel, Expired paracetamol, Polarization, Adsorption, Corrosion inhibitor.

\section{FULL TEXT}

(C) 2021 The Authors. Published by ESG (www.electrochemsci.org). This article is an open access article distributed under the terms and conditions of the Creative Commons Attribution license (http://creativecommons.org/licenses/by/4.0/). 